\title{
Cultural resources and sustainability: improving city planning and urban preservation in a Mexican city
}

\author{
A. Acosta \& J. C. Parga \\ Department of Habitat Design, \\ Autonomous University of Aguascalientes, Mexico
}

\begin{abstract}
In several Mexican cities a progressive environmental deterioration is evident. An understanding of sustainability is crucial to the preservation and management of historic town centres. The objectives of this paper are to examine how urban heritage is defined and to discuss the possibility of sustainability within the model of a Mexican City, Aguascalientes. The foundations of sustainable development and urban preservation planning are discussed in support of the objectives. We present, as a central hypothesis, that a balance of specific variables is needed in order to preserve urban heritage. Those variables are addressed as environmental, economical and societal. Statistics and data from a large economic system are referenced and linked in with local indicators. Furthermore we analyze water table problems, domestic and commercial waste, air pollution, Gross domestic product (GDP), income, poverty, gender equity, population growth, education and cultural identity. The paper shows what happens in Aguascalientes, in order to illustrate general principles in Mexico, for example: opening of streets and irreversible loss of urban heritage - at this rate we will end up with only facades, as the old western films and relevant buildings still standing. The recurrent crisis of urban planning requires new development alternatives. Quality of life is the product of improving urban services, health, income, environment and preservation of cultural elements. Efficiency, growth and stability, are basic issues of the economic dimension of sustainable development, but present no satisfactory rates, so the applicability of the concept will depend on improving these conditions in the future. Social backwardness
\end{abstract}


requires a rethinking of economic policies. Cultural heritage should become an important part of the government's sustainability policy.

Keywords: sustainability, city, preservation, urban heritage, Mexico.

\section{Introduction}

One of the challenges of sustainable development is the role of historical and cultural aspects versus several processes of our times like: economic, technological, environmental, sociological, etc. that impact and transform the city. It is important to seek alternatives in the field of urban and regional planning, combined with conservation of historical places. The main concern is to understand how sustainable development and social components, ecological and economic returns are linked to the conservation and management of the historic town centre and the city of Aguascalientes. It was necessary to rely on relevant conceptual aspects of sustainable development and urban planning in order to frame the problem and come on land more flat and free of obstacles, including the epistemological concerns, paraphrasing Gaston Bachelar. It is of particular importance to ask ourselves in this field how urban heritage is articulated with sustainability. The concept of sustainable development has three major variables: environment, economy and society, fig 1.

The environmental section corresponds to studying the ecological environment, and analyzing the main indicators. Indicators should allow plans and efforts to guide development in historic areas and towns to a balance with the environment. The variables involve the use of natural elements: water, soil and air. Historic town centre present a lack of care, such as: the new opening of streets and irreversible loss of architectural and urban expressions of quality. We will consider and suggest some relevant actions from the government to begin the process of sustainable development in the historic center.

The recurrent crisis of urban planning requires new designs or development alternatives. Sustainable development should include a qualitative change. The local level is critical in this process for the recovery of cultural identity. We will analyze the concept, including its variables in the city and in the historic town centre. Quality of life will be the product of improved indicators in urban services; health; income; environment and preservation of cultural buildings.

\section{The lowering of water tables}

From a national perspective a high percentage of Mexico's population is located in semi-desert areas. The first population census of the twentieth century in Mexico shows that a third part of the people was living in the countryside, but now this is inverted. The cities carry a special problem: the supply of drinking water. The National Institute of Statistics, Geography and Informatics (INEGI) mentions that nationwide there are 101 over-exploited aquifers. $36.6 \%$ is extracted from groundwater for all uses, while water that is groundwater recharged or infiltrate represents only $17.3 \%$ of total available water [2]. 


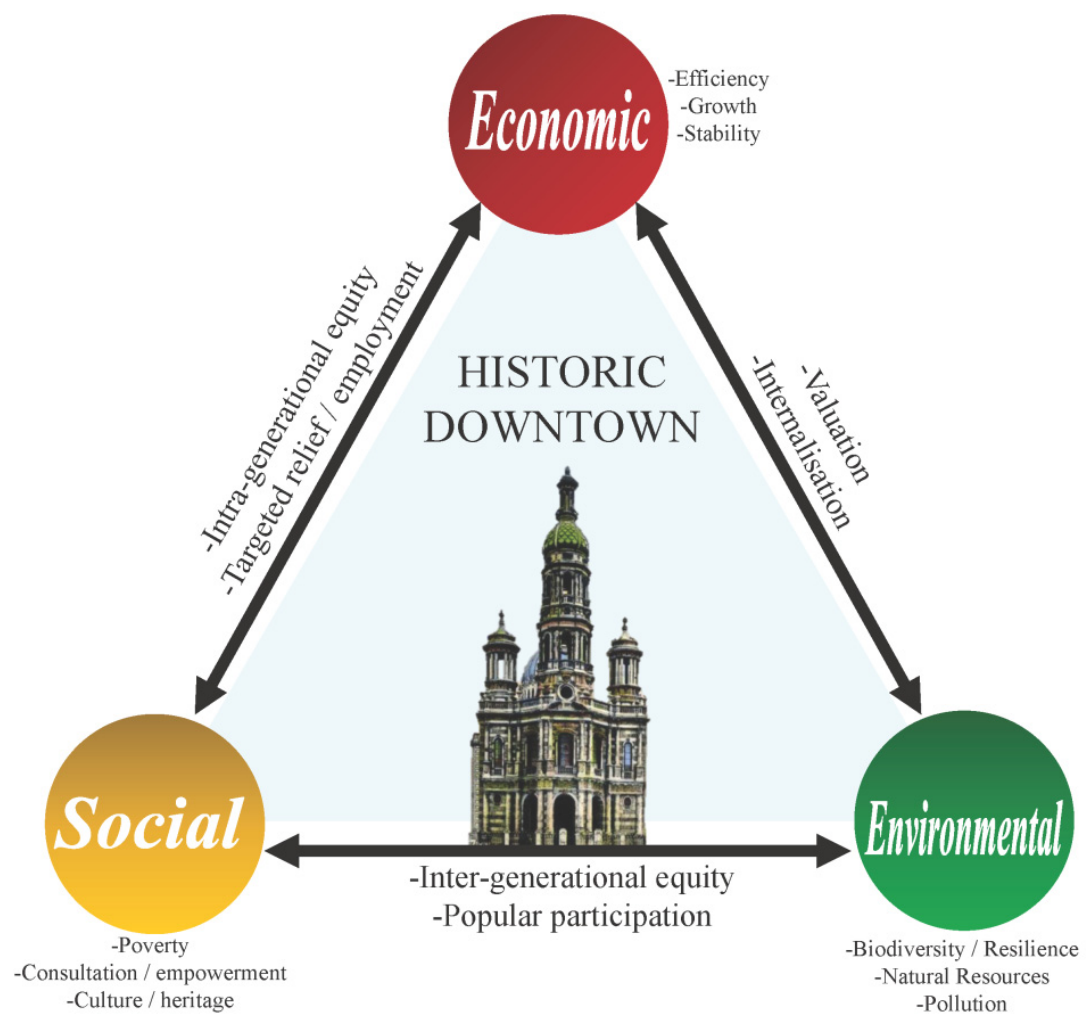

Figure 1: The concept of sustainable development has three main objectives. We place cultural heritage in the middle. (Original source: Munasinghe [1].)

The city has a domestic consumption of 186.40 liters/person/day, below the national average of 216.60.The lowering of water tables is accelerated to a speed of 2 meters deep annual average. Rainfall in the region is not sufficient to produce water table recovery; this turns into an uncontrolled situation. Sustainable development is directly linked to this process, which means, if there is not adequate water recharges it puts in danger ecosystems and life forms, including future generations. It is necessary to have less impermeable systems in city streets to recharge groundwater, improving natural recovery cycles. The recharge of water tables also depends on the rainy seasons. In late 2009 and early 2010 there were good harvests and decreased the drought. The Government stated that it obtained a high yield of vegetables and fodder [3], in this century.

The search for alternatives to achieve a balance must be a priority in future government policy locally. The restoration of the aquifers will not return to their original levels in our times, however we can think of applying a sustainable 
concept to achieve the top level in which there can be a balance between extraction and consumption. Aguascalientes now has an average efficiency of water use Approx. $13.000 \mathrm{~m}^{3} /$ ha close to the world average of $12,000 \mathrm{~m}^{3} / \mathrm{ha}$. This means that consumption is not so alarming, but it is time to use new methods of recycling and recovering water, because the water issue draws attention nationally and worldwide.

\section{Soil and air pollution}

The gradual reduction of arable land is directly linked to environmental sustainability. This phenomenon increases with population growth. Some small towns of the nineteenth century in Mexico had orchards supplying food to their population, but the growth of cities did not measure the loss of this sustainable relationship. In many cases the cultivation of the vine was common practice around the small towns.

At Aguascalientes several suburbs started occupying the west side (agricultural areas). This action changes the cultivated land per capita, resulting in a greater emphasis on current agricultural methods and food imports. Some large industrial cities districts and isolated rural factories also produce a large amount of garbage.

The Federal Bureau for Protection of the Environment (PROFEPA) and the Environment Bureau and Natural Resources (SEMARNAT) have a full record of the generation and location of such waste, although it requires more applied scientific research in this area. For example, the area of railroads in Aguascalientes, presents in the underground a high level of pollution by deposits of several minerals and coal, accumulated for more than 100 years, without knowing for sure if it remains contained within a few feet deep or they are moving to the aquifers. The performance of environmental impact assessments (EIAs) for specific areas and for those with high potential of pollution is important. The EIA should also be required in the establishment of new factories in the city. Managers of Three Centuries Park, in the old railway workshops, are now making a major effort to clean up the area and confine these wastes. While there has not been an accident in this entity as in Chernobyl, the established industry generates pollution. The Mexican Grand Central Factory that arrived in the late nineteenth century also generated a large amount of industrial waste. Some buildings are located over this waste.

The wind carries dust particles and they gradually cover the surface of materials. In that way the ancient pyramids of Mesoamerica were covered. In a similar way the air inside the cities contains a certain amount of pollutants that cover materials, and also human beings breathe. It is the carbon dioxide that contributes to the greenhouse effect and global warming up. Cities that have more air pollution problem in Mexico are: Mexico City, Guadalajara, Monterrey and Puebla.

The 250,000 vehicles at the beginning of this century in Aguascalientes began to produce a lot of pollution during the day. Now there are more than 400,000 units across the state, thus increasing air pollution. Depending on the volume of 
maximum and minimum concentration of major air pollutants were recorded between 2000 and 2005 a maximum of Nitrogen Dioxide (NO2) of 45 ppb (parts per billion) and a minimum of $31 \mathrm{ppb}$ dioxide Sulfur (SO2) a maximum of $44 \mathrm{ppb}$ and $31.5 \mathrm{ppb}$ minimum, carbon monoxide (CO) up to $2.1 \mathrm{ppm}$ (parts per million) and a minimum of $1.7 \mathrm{ppm}$ [4].

All these values are low, according to the standard (IMEC), which respectively has a value of $210 \mathrm{ppb}$ for nitrogen dioxide, $130 \mathrm{ppb}$ for sulfur dioxide and $11 \mathrm{ppm}$ for carbon monoxide. This indicates that air pollution is at permissible levels, but continuity is desirable to control gas emissions from motor vehicles and factories located in the city and its environs; coupled with proper planning public transportation routes. The Intergovernmental Panel on Climate Change (IPCC) at its meeting in May 2007 warns that the gases that produce the greenhouse effect may stabilize no later than 2015 , so that the causes are not so catastrophic. The $\mathrm{CO} 2$ pollution per capita in Aguascalientes and in Mexico is relatively low compared to highly industrialized countries.

\section{Income and unemployment, the global-local}

The arrival of transnational corporations to Latin America seeks to hire people skilled in certain areas or with a great adaptation capacity. However, this has generated marginalization. There are some positions that place unemployment in the social fields, but there is no doubt that the indicators have a strong relationship with the economic field.

It is positive to analyze indicators such as gender inequity, population growth and its relationship to the historic town centre, education and its role in sustainable development as well as the various Health Sector components and the importance of cultural identity in society and the transfer of these aspects to future generations. Intergenerational equity is central to the idea of sustainable development. Economy in Mexico requires a visionary approach to medium and long term, including reducing the polarization between rich and poor to strengthen the middle class.

The study of income also can be placed as a social indicator in terms of sustainable development, but by the type of indicators comprising the model used is better to place it within the economy. The income level varies by city or region, with several variables that lead to fluctuate positively or negatively. The $18 \%$ of the population in Mexico concentrated more than the $50 \%$ of national income. Ornelas says: 'If the poor and middle classes have decreased their share in income, the fifth of Mexican households (it is the high-income), they started getting 49.5 percent of income in 1984, in 1992 possessed the 54.2 percent. Finally, in the indicated period households and medium low-income of Mexican society were systematically impoverished by the neoliberal policy and, rather, along the neoliberal era has only improved their share in income groups who were already rich' [5].

The percentage of poor people in Mexico is high; it is composed of $60 \%$ of the population, half of which $(30 \%)$ is in extreme poverty. Mexico has accelerated the disparity in income; continuing with neoliberal policies and 
globalization orthodox application. The awareness of employers about the income disparity not disturbed them, very few people talk about it. Ted Turner (owner of CNN) says about this: 'All the money is in the hands of these few rich people (referring to the megamillionaires), and none of them drop anything. That's dangerous for them and for the country. We will live a new French Revolution in which another Madame Defarge knitting contemplate how these people are taken to the town square in bullock carts and boom, their heads blown' [6]. The precarious situation is reflected in the major cities because of the importance of globalization and by the simple fact that most large industries are multinationals, so their labor relations policies are similar in the best cases, and worse in most of them.

In the period from 1990 to 2005 there were some variations in terms of the Economically Active Population (PEA) and inactive in the State of Aguascalientes. The population aged 12 and over by activity status, that is 483.625, in the year 1990 the total was 217.092 PEA; 212.365 from which were employed and unemployed 4.727; the economically inactive population was 258.096, it was more than the half [7]. In contrast to 2000, where the population aged 12 and over by activity status was of 659.863 habitants. Of which the PEA was 335.042, 331.083 of them were employed and unemployed 3.959; the economically inactive population was 322.142 , that was less than half [8]. This indicates that in fifteen years the inactive population has declined slightly in proportion; allow incentive situation and this does not mean that family incomes have improved. Unfortunately there are several factors that affect local issues because of the macroeconomic indicators, such as the link between unemployment and GDP. Nestor Duch said that the Open Unemployment Rate (TDA) is closely correlated with its own history and changes in GDP in the entity: 'The function expressing such networking is, in symbols, as follows: TDA $=f(T D A T-1, T D A T-2, A D-3, P I B T)$. This is the Open Unemployment Rate in the period $T$ is a function of the own rate from the three previous periods (quarters) and the behaviour of GDP in the same level of $T^{\prime}$ ' [9] so the decrease in the percentage of inactive people is contradictory with the unemployment rate, and there is a very high degree of dependence with changes in GDP. Aguascalientes is among the top five states in the country in the State Competitiveness Index 2008, according to the Mexican Institute for Competitiveness. The unemployment problem requires both sensitivity and solidarity, a word overused in the last decades in Mexico, but with great meaning of unity.

In the historic areas, happens something similar to the global, monopoly groups are owners of several buildings in the area of monuments, most of the neighborhood have been displaced mainly by commerce expansion, a portion of the people, who live in extreme poverty, live in the historic town centre but on the streets, sleeping outdoors on park benches, seeking shelter from the weather under bridges, abandoned buildings, canopies or building entrances. The socioeconomic contrasts are also relevant in the old town.

Poverty is an urgent item on the local agenda, regional and global development policies. A developing country must include substantial and sustainable policies attending poverty. Social polarization may emerge from 
income inequity. In Mexico, 60 percent of the population is poor. According to the Financial Journal there are only 19.5 million people with no gaps in any of the aspects that indicate poverty (housing and equipment, food, income, health, education and social security [10]. The INEGI reported, in connection with the World Population Day, that Mexico reached 107.6 million, from which 50.9 percent are women and 49.1 are male [11]. What can be done on a local level -historic town centre? First of all, we can say one of the main causes of poverty in Mexico is the lack of solidarity. The gap between rich and poor is slowly increasing, Guzman says: 'The first world intellectuals designed new ethical concepts that take into account the ecological relationships in the biosphere, while the old ethics of solidarity and equity among human beings become obsolete objects of study for philosophers and historians' [12].

The quality of life of the dispossessed is not the appropriate. The causes of poverty directly involve government policies and depend largely on macroeconomic strategies. The first cause of poverty that is normally addressed is unemployment. How will reduce unemployment if the forces that generate it do not acquire a sense of overall progress? Overcoming this obstacle is the stone "key" in the guidelines from development.

It is said that sustainable development came from an ecological concerns about the environment. And we explained that energy stocks tend to decline in their production. The planning of these spaces should also involve social issues as the decline not only in the ecological side, there is social decay reflected in the sustainability indicators, including and perhaps the most serious is the one about poverty. Thinking in the urban heritage aspect, we see that not all people who live in the historic town centre have a job. There are still poor neighborhoods and certain neighborhoods with poor sanitation, generally occupied by people with temporary jobs and low payment.

The shadow of the economic instability affects urban heritage, causing a gradual disappearance of historic buildings. Neighborhoods actually tend to disappear because they are unhealthy and overcrowded, but has not thought about what will be done with the people who habit them, is it going to marginalize them in shanty towns? Or will they reallocate new houses? Local regulations do not address the protection of the dispossessed; much less ensure their survival.

\section{Education and research}

In the pursuit of sustainable development one of the most important indicators is the percentage of economic resources allocated to education and research. In fact, State contribution has changed very little in recent years. In 1990 the national expenditure on education was $\$ 29,722.70$ million pesos, this was $4.0 \%$ of the GDP, taking into account that GDP got to $738,897.50$ million current pesos. For the year 1999 the national expenditure on education increased to $\$ 257,572.90$ million pesos; showing an increase in the contribution of $5.6 \%$ of GDP. In 2007, from the 30 countries of the Organization for Economic Cooperation and Development (OECD), Mexico occupied the last position in the 
heading of education, with only 410 points, below Turkey (424) and Uruguay (428). Finland was the first position with 563 points [13]. In recent years an effort is made by public institutions in relation to research, technology and project development, but it is not enough. This means that little research is practice in Mexico. Without research projects the sustainable concept remains unsure. La Jornada Newspaper says 'Week In Science, Technology and Innovation, by directors of the National Autonomous University of Mexico (UNAM), Autonomous Metropolitan University (UAM) and the National Council for Science and Technology (CONACYT), among others, who noted Mexico is intended half of the resources channelled to other nations in scientific research ... Meanwhile, Gabriela Dutrénit Bielous, Research Professor at the UAM and who was responsible for organizing this forum, says that Mexico spends just 0.5 percent of GDP to development of science, but in countries like Brazil or India they spend more than one percent of this activity, leading universities and research institutes to defy their lack of resources to develop research. She explained that there was lack of commitment from the productive sector to advance technology and was questionable on the eve of the budget discussion in the House of Representatives, whether it will increase the amount allocated to universities' [14].

Elementary schools in the historic center are now saturated, and the coefficients of land use are high, even though the residential population of downtown crashed. The few people who live in the historic town centre tend to be well established, and there are families with no children. Higher educational levels are situated at the urban periphery. The most educated people in Mexico live in the cities rather than in the countryside.

\section{Cultural identity}

Sustainable development in cities should include preserving cultural identity, and urban architecture values are significant. The relationship between individual and society is important, but preserving the city by restoration policies makes this relationship more consistent. Local regulations do not require historic property owners to reuse the abandoned houses for residential destinations, allowing them to define the future uses as they fit with the economic benefits. This implies in many cases, traditional spaces contrast with current space usage needs, sometimes incompatible.

With the decline of the welfare state, neoliberal forces began to have a presence more strongly in the historical center in the late twentieth century, moving from residential to commercial use and influencing greatly in real estate. The trade was gradually appropriated by the central spaces and began to expand, Mantecón says: there is a relationship between the real estate to the transformations in the central area and direction of state policies towards them. Several investigators have suggested that it is not the financial capital, which has been in the centre but the commercial and certain fractions of productive capital, whose coalition is the one that has promoted its generation [15] under the slogan of 'progress'. Why do we insist on cultural identity? Global flows of 
consumerism are not able to establish a good dialog between cultural identity and profits. Sustainable development should be an answer to materialize the benefits and urban services for people. Possibly society have to take the example left by Jacques-Yves Cousteau in defending the environment, but now for the rescue of culture. Identity in the historic town centre is produced by distinctive buildings and the urban architecture of the city, with specific designs that reinforce its presence in the collective memory, and yet mean an encounter with the past, mean location references and an aesthetic feature that sometimes is ignored.

The city image is changing slowly with new buildings and appearances that move away earlier monuments, but changes, in most cases of urban heritage, is negative for inter-generational equity; for example, the old covered sidewalks with gates for pedestrians, that were used to protect the people from the rain and sunlight, were demolished to build new walls. Vertical windows were replaced in part of the historic town centre by horizontal openings. The new buildings in the historic town centre show excessive use of glass and steel, showing contemporary architecture with no typological unit, that it is now difficult to recognize, and what about the advertizing? Now it is becoming bigger and we see it everywhere, in tall buildings, bus stops and in urban transportation. Now the art of making new facades seizes part of the old streets in the historic centre, but some of them look like reproductions of old buildings, but contemporary inside. The indicator: 'cultural identity' of sustainable development was measured through qualitative changes of the urban heritage in this case. Is sustainable development a viable alternative for the city of Aguascalientes? The fact is that the following areas should substantially improve: economy, society and environment. No doubt we have started ignoring the importance of cultural identity, but it is still part of the DNA of Mexican society.

\section{Conclusions}

After analyzing the possible application of the sustainable development in Aguascalientes, we can say there is lack of quality in most of the economic indicators and city planning. Efficiency, growth and stability, basic aspects of the economic dimension of sustainable development, show no satisfactory results, so the applicability of the concept will depend on improving these conditions in the future. There is a cultural decline of the historic centre. The vision of sustainable development must include not only the utilitarianism of the buildings, but involve cultural aspects relevant to the individual education.

Economic crisis causes a gradual loss of purchasing power. Also the combination of several factors: low productivity reflected in GDP, the impact of external debt and paltry income; lack of quality of life; the lack of solidarity, abuse banking users, consumption patterns, deterioration of the retirement system, the excesses of the internet and loss of political credibility. Therefore, it is convenient to reorient consumption patterns and thus to reconstruct the social structure. Technological dependence has produced considerable changes in the contemporary way of life; vehicles, computers, internet, video games, 
telephones, tablets, e-books, video calls, game consoles, etc are devices that influence public and private spaces. It is also necessary to start a culture of management of the new electronic waste unused, known as E-waste. The three " $\mathrm{R}$ " can be applied in this case: reduce, recycle and reuse. Economic instability does not allow the generation of a guideline towards development and spreading out of cultural aspects.

Gender inequity is an issue that requires special attention. Women participate more progressively within the Economically Active Population (EAP) in Mexico, but differential treatment persists and the informal economy of traders in the center of the city of Aguascalientes is benefited by the low wages of employees in counter, mostly women. In the historic centre, systematic depopulation is reflected in abandoned houses or transformed into new incompatible uses within the area.

Aguascalientes climate also is changing slowly, with atypical manifestations, such as heavy rains in the dry season or increased solar radiation in summer, causing high temperatures and increasing exposure to UV rays from the sun.

Contributions from the federation in terms of education represent a small percentage compared to other countries. Juan Ramón de la Fuente said that there was a lack of interest in encouraging the culture, education and science.

Mass media does not contribute to education and people naively turn on the TV expecting to find reality in the news, but to paraphrase Jean Baudrillard, there is a hypertrophy in the communication, which should be put into question the veracity and the reality shown in the images emanating from unfounded serious findings.

The progress of medicine and the government's effort to improve the health of its inhabitants in the second half of the twentieth century, favors certain conditions to start a real development. Contributions in economic terms are relatively low in relation to the GDP of developed countries, and inconsistent in relation to the real world.

We need a scientific vision at universities in Mexico to assess the relevance of the human intervention in nature and to alert their consequences. This will recognize natural resource scarcity and why human changes affect the contexts, dynamism and natural interaction. Also to recognize the damage caused to the environment and seek for mechanisms to make events reversible, or at least stop the serious damage. It is appropriate to recognize the anthropic principle, the one that refers Stephen Hawking, saying that humans are able to live in this universe, but gradually we alter the planet. This change is observed in the three scales of analysis made so far in the text: the local, the national and global, which are related to each other. The sustainability concept allows a dialog among these levels and further allows the inclusion of cultural resources that is needed in today's society.

In the historic town centre level, part of the population does not have adequate financial resources, in addition to the indigent, so the scope is limited to the benefits of health sector, so its inclusion is necessary and to avoid displacement on shanty relegated areas of the city. The use of the vehicles in the old towns must give way to pedestrian communications, taking advantage of the 
existing infrastructure. In this way city administrators can reduce the emission of toxic gases and pollutants. Also green areas within the city should be increased. Sustainable development of urban heritage goes beyond physical intervention, this involves: economic, social and environmental conditions that need further attention and government action.

Even though the concept of sustainability seems utopist, it approaches a shortterm progress that could be seen as an opportunity in local urban planning. The proposals shown in this text represent the beginning of a considerable work in city planning, in terms of sustainable development, and some actions can be integrated into the development agenda.

Extinction of the historic centers should not be part of the evolution of cities. We must learn to read the history that tells us what happened and what is happening in the city, including its social problems, to bring innovative urban designs, relevant and applicable alternatives for heritage revaluation.

Maybe it is time to start considering most of the city as urban heritage, and not only in the historical area. There are modern residential areas that have outstanding elements with regional identity; also newer buildings and excellent urban architecture for example the INEGI, the Discover Museum and the main Theatre of the Aguascalientes City. There are engineering works such as bridges and industrial buildings that can bring in cultural integration. May be it is necessary a new way of looking at the city in which multiple designs are part of the context. The streets, buildings, landmarks, including infrastructure, are part of a social heritage, so it correspond to the citizens to take care of them. Under this approach it would be more affordable to have sustainable environments and we can focus on the future of Aguascalientes with optimism.

\section{References}

[1] Munasinghe, M. Environmental Economics and Sustainable Development, World Bank Environment, Paper Number 3, The World Bank: Washington, D.C., pp. 2-4, 1993.

[2] El Hidrocálido Newspaper, Devours the country groundwater nationwide. From 32 rose to 101 the number of overexploited aquifers, Saturday March 20, p. 4, 2010.

[3] El Hidrocálido Newspaper, It was the best winter crop of this century, Friday April 5, p. 5, 2010.

[4] INEGI, Aguascalientes Statistical Yearbook, p. 38, 2001.

[5] Ornelas, J. Neoliberalism really exists, BUAP: Mexico, p. 50, 1997

[6] Martin, H. P. \& Harald S, The trap of globalization, the attack on democracy and welfare, Taurus: Mexico, 1st. Reprint, p. 238, 2000.

[7] INEGI, Estados Unidos Mexicanos, One Hundred Years of Population Censuses, Mexico, p. 256, 1996.

[8] INEGI, Aguascalientes Statistical Yearbook, p. 251, 2001.

[9] Duch G. N., The labor market in the metropolitan area of Aguascalientes, CIEMA / SIHGO, p. 175, 1998.

[10] El Financiero Journal, March 12th, Mexico, 2010. 
[11] El Universal Journal, July 10th, Mexico, 2009.

[12] Guzman A, Problems of development, No. 122, Jul/Sep, UNAM: Mexico, p. 82.

[13] http://www.exonline.com.mx/diario/noticia/pulsonacional/primera. December 4th,2007.

[14] La Jornada Newspaper, Tuesday, September $23^{\text {rd }}, 2008$.

[15] Mantecón, R., Rescuing historic towns centres. Preserving history, CITIES No. 8, p. 17. 